\title{
A ORGANIZAÇÃO MUNDIAL DA SAÚDE: DO CONTROLE DE EPIDEMIAS À LUTA PELA HEGEMONIA
}

\author{
THE WORLD HEALTH ORGANIZATION: FROM CONTROLLING EPIDEMICS TO \\ STRUGGLING FOR HEGEMONY
}

Gustavo Corrêa Matta 1

Resumo Este artigo tem o objetivo de discutir o surg i mento da Organização Mundial da Saúde (OMS) como uma agência especializada de âmbito internacional, seu funcioname n to, os principais marcos históricos e políticos e as estratégias de luta pela hegemonia no cenário sanitário internacional. Foi realizada uma pesquisa bibliográfica e documental através de documentos da OMS, discursos de seus diretores gerais, textos de apresentação institucional, artigos e editoriais. Dois momentos fundamentais na influência da OMS nas políticas de saúde internacionais foram ident ificados: o Programa Saúde para Todos (2000) e a política promovida pela gestão Gro-Brundtland (1998-2002) na direção da OMS, período em que são realizadas profundas transformações nas políticas de saúde internacionais e, em especial, em que há a necessidade de estabelecer nexos metodológicos e políticos com as estratégias de globalização da economia e com as políticas de saúde globais 2 .

Palavras-chave Organização Mundial da Saúde; saúde internacional; globalização; agências internacionais; mundialização do trabalho em saúde.
Abstract The objective of this article is to discuss the emergence of the World Health Organization (WHO) as an international specialized agency. It also debates how the organization operates, major historic and political landmarks and its strategies in the struggle for hegemony in the international sanitary scenario. For such, we researched WHO's documents, directors-general's speeches, texts introducing the institution, articles and editorials. Two specific moments were of fundamental influence to WHO's international health policies: The program Health for All (2000) and the policies fostered by the Gro-Brundtland administration (1998-2002). In this period, not o nly pro found transformations in international health policies were undertaken, but also, the need to establish political and methodological links to the globalization of the economy and the global health policies emerged.

Key words World Health Organization; international health; globalization; international agencies; globalization in health work. 


\section{Introdução}

A Organização Mundial da Saúde (OMS) é uma agência internacional que influencia, monitora e avalia as políticas de saúde em todo o mundo. Nesse sentido, o esforço de cooperação técnica e científica é a principal estratégia para influir nos sistemas nacionais de saúde.

A noção de agência internacional é utilizada neste trabalho conforme a definição de Mattos (2001), a qual suge re a participação de no mínimo três países na constituição e sustentação financeira e política de uma organização. Os estados nacionais que participam das agências internacionais são denominados países membros (ou estados membros).

Esperava-se que a OMS, como uma agência especializada das Nações Unidas, exercesse uma certa liderança no campo da saúde internacional, mas, com a entrada do Banco Mundial nesse cenário3, a luta pela hegemonia no mercado de idéias para a saúde tornou vital para a OMS a revisão de seus objetivos e suas estratégias, além de sua reafirmação como uma organização que orienta as ações em saúde em todo o mundo.

\section{História e política}

Segundo um texto de apresentação sobre a história da OMS (WHO, 2002a), desde o século XIX várias tentativas de organizar uma instituição de caráter internacional para tratar dos problemas sanitários do mundo foram empreendidas. Diversos autores apontaram diferentes explicações para o surgimento de fóruns e organismos de cooperação internacional para a formação de consensos em saúde e ações estratégicas para o controle e prevenção de enfermidades, mas todos apontam como um dos fatores fundamentais "o crescente fluxo de mercadorias e pessoas, assim como de doenças" (Lima, 2002, p. 25) devido à industrialização e à expansão dos mercados nos grandes centros urbanos.

O esboço dessas organizações teve início na Europa, em decorrência da epidemia de cólera, sendo realizada em 1851, em Paris, a primeira Conferência Internacional de Saúde. Essa reunião tinha o objetivo de produzir um Consenso Internacional de Saúde, que não teve êxito. Em 1892, este consenso foi adotado, mas restrito unicamente à cólera.

Lima (2002) aponta que, por conta do impacto das epidemias de cólera e fe bre amarela na América Latina, realizou-se uma convenção sanitária em 1873, em Montevidéu, com a presença de autoridades sanitárias brasileiras, argentinas e uruguaias, determinando medidas comuns de prevenção da cólera asiática, da febre amarela, da peste e do tifo. Em 1887, esses países realizaram no Rio de Janeiro um novo encontro, onde foi estabelecida a Convenção Sanitária do Rio de Janeiro. 
Outros esforços foram envidados no sentido de produzir consensos quanto à prevenção e classificação de doenças, bem como quanto à organização de instituições sanitárias internacionais. Entre as principais, a OMS cita o International Sanitary Bureau, em 1902, sediado em Washington (EUA) e atualmente conhecido como Organização Pan-Americana de Saúde (Opas); o Office International d'Hygiène Publique (OIHP), em Paris (1907); e The Health Organization of the League of Nations, sediado em Genebra, Suíça (1919).

É interessante perceber que a preocupação dessas organizaçõesresidia no controle e na prevenção da transmissão de doenças entre os países, como, por exemplo, no estabelecimento de um Consenso Sanitário Internacional para a navegação aérea.

No período imediato do pós-guerra, ocorre o surgimento de diversas instituições de âmbito mundial, subsidiadas pelos países aliados, como a Organização das Nações Unidas (ONU), em 1945, e o Banco Mundial, em 1944. Tais agências consistiam em um arcabouço institucional de agências internacionais, pensadas como sustentadoras da nova ordem mundial no pós-guerra.

Um texto da OMS (WHO, 1947) aponta a incapacidade das organizações sanitárias existentes na época em fazer frente aos novos desafios que o campo da saúde apresentava em todo o mundo, sendo necessária a constituição de uma única instituição intergovernamental de saúde com a estrutura e sob as diretrizes da ONU.

\footnotetext{
“Todas essas instituições eram limitadas no espaço, no tempo ou em suas funções, tornando claro que o final da Segunda Guerra Mundial devia assistir à criação de uma única organização mundial de saúde de caráter intergovernamental, no interior da estrutura das Nações Unidas, a qual deveria assumir não somente a responsabilidade das instituições pioneiras, mas ter a amplitude das necessidades colocadas pelos novos problemas deixados pela guerra e as mudanças das condições do mundo pós-guerra"4 (WHO, 1947).
}

O período pós-guerra impôs uma necessidade irrefutável, e imediatamente subordinada à ONU, da constituição de ações de colaboração internacional para o cuidado e o restabelecimento das condições de saúde em populações afetadas pela guerra e para o desenvolvimento de medicamentos, procedimentos e métodos diagnósticos iniciados pelos avanços ocorridos durante as guerras mundiais.

Durante a realização da Conferência das Nações Unidas sobre Organização Internacional, em 1945, em São Francisco (EUA), foi aprovada a proposta encaminhada pelo Brasil e pela China para "estabelecer uma nova e autônoma organização internacional de saúde" (WHO, 1947). 
Em 22 de julho de 1946, durante a Conferência Mundial de Saúde em Nova York, com a participação de 61 países, foi aprovada a Constituição da Organização Mundial da Saúde. Esta dispõe sobre os objetivos e regras de funcionamento da OMS. Em 1947, a comissão interina da OMS organiza uma assistência ao Egito para o combate à cólera.

Finalmente, em 7 de abril de 1948, a Constituição da OMS entrou em vigor com a ratificação da participação de 26 dos 61 países membros. Durante a Primeira Assembléia Mundial de Saúde, realizada em Genebra, delegações de 59 governos tornaram-se membros da OMS. Sete de abril passou a ser, então, o Dia Mundial da Saúde, celebrado a cada ano.

A unificação das dive rsas instituições sanitárias internacionais na OMS não foi tão simples como leva a crer a narrativa histórica construída pela organização. A Opas, já em atividade desde 1902, possuía uma organização forte, com estrutura e orçamento muito superiores à recém-constituída OMS. A Opas reivindicava autonomia frente à OMS devido a sua capacidade institucional e técnica de sustentação.

\footnotetext{
“Não foi simples o estabelecimento do papel a ser desempenhado e a garantia de alguma autonomia de ação à Opas. Um fator decisivo foi o aumento de seu orçamento com base na elevação das contribuições dos países latino-americanos, principalmente a Argentina, o Brasil e o México. A capacidade de sustentação da Opas, em contraste com o exíguo orçamento da OMS, pesou definitiva mente na negociação entre as duas entidades. Em julho de 1948, durante a $2^{a}$ Assembléia Mundial de Saúde, firmou-se acordo entre o diretor geral da OMS, Brock Chisholm, e Fre d Soper, diretor da Opas, pelo qual esse organismo, sem perda de sua identidade, converteu-se em Oficina Regional para as Américas da OMS" (Lima, 2002, p. 70).
}

Sob a rubrica das Nações Unidas, a OMS inicia, já em suas origens, a luta pela hegemonia ${ }^{5}$ no campo da saúde, tanto no aspecto político quanto na construção de normas e consensos técnicos internacionais.

O esforço inicial da OMS foi rever os Consensos Sanitários Internacionais, uniformizando classificações de doenças e seu potencial epidêmico. Em 1969, essas re gras e classificações foram nomeadas "Regulamentos Internacionais de Saúde". As principais doenças que deveriam ser reguladas e controladas pela OMS e seus países membros eram cólera, peste, varíola e febre amarela.

A partir de 1973, observa-se uma primeira revisão da política da OMS em relação a sua influência sobre os países membros. Durante a 26 ${ }^{\mathrm{a}}$ Assembléia Mundial de Saúde, foi apresentado um relatório do grupo executivo que concluía que havia uma grande insatisfação com os sistemas de saúde. A assembléia então decidiu que a OMS deveria contribuir, mais do que assistir, com seus países membros no desenvolvimento de normas práticas para os sistemas nacionais de saúde. 
Em 1974, a OMS expandiu seu Programa de Imunização Infantil, com ênfase na poliomielite, sarampo, difteria, coqueluche, tétano e tuberculose.

Uma nova política da OMS foi lançada em 1977, com o objetivo inicial de propiciar um padrão de saúde que permitisse a todas as pessoas terem a oportunidade de levar uma vida social e economicamente produtiva. Em 1978, este projeto intitulado Saúde para Todos no Ano 2000 foi lançado durante a Conferência de Alma-Ata, que adotou como carro-chefe dessa política, em uma parceria entre a OMS e o Fundo das Nações Unidas para a Infância (Unicef), a Declaração sobre Cuidados Primários em Saúde.

O planejamento do Saúde para Todos contava com o apoio financeiro e político de instituições governamentais, privadas e não-governamentais,além de comunidades científicas e acadêmicas. A OMS tentava consolidar-se como uma organização que não apenas assistia seus países membros, emuma perspectivadoença-centrada, mas também, e agora principalmente, intervinha e propunha políticas e estratégias sanitárias e sociais. Essas ações teriam o apoio político e econômico de instituições internacionais, como a ONU, e o respaldo científico das comunidades acadêmicas e de pesquisa, sendo instituídas em nome da saúde e da ciência, influenciando direta mente as políticas sociais e econômicas empreendidas pelos estados nacionais.

Para fundamentar esta nova direção política da OMS, que teve início em 1973, o Saúde para Todos foi inspirado em um dos princípios constitucionais da OMS: “O gozo do maior nível de saúde que se possa alcançar é um dos direitos fundamentais do ser humano, sem distinção de raça, religião, ideologia política, condição social ou econômica" (WHO, 1946).

É interessante notar que a mudança de rota na OMS se dá durante a $26^{\mathrm{a}}$ Assembléia Mundial de Saúde, em 1973, marcada pela saída do brasileiro Marcolino Gomes Candau da direção geral da OMS (1953-1973) e a eleição do dinamarquês Halfdan Mahler (1973-1988). Mahler foi assistente da direção geral durante a gestão de Candau, dirigindo o Projeto de Análise de Sistemas de Saúde. A gestão de Mahler foi marcada pelo lançamento e pela execução do Saúde para Todos e por suas estratégias de implantação junto aos países membros, com ênfase na atenção primária e na imunização infantil.

Em 1978, a ONU, simultaneamente à realização da Assembléia Mundial de Saúde, reafirma que a saúde é a alavanca poderosa para o desenvolvimento socioeconômico e a paz. A ONU repete a estratégia em 1981, adotando a Estratégia Global para Saúde para Todos no Ano 2000, solicitando o apoio de outras organizações internacionais interessadas em colaborar com a OMS.

Apesar da grande importância de Alma-Ata, a OMS, ao longo dos anos 80 - como se verá em detalhe adiante —, foi perdendo sua influência. De um lado, a mudança da direção do Unicef, em 1981, fez com que esse fundo se afastasse das teses unive rsalistas de Alma-Ata e assumisse uma proposta de difusão de um pacote mais seletivo de ações voltadas para a redução da 
mortalidade infantil. Em torno da iniciativa do Unicef, aglutinaram-se grandes volumes de recursos (do Banco Mundial, de entidades privadas e de agências de ajuda ao desenvolvimento). Nesse sentido, o Unicef assumia um papel de destaque no cenário internacional, ao mesmo tempo em que a sua iniciativa 'diluía' a ênfase da OMS no desenvolvimento de sistemas (Mattos, 2001).

Logo no início da década de 1980, por sua vez, o Banco Mundial - que rapidamente vinha elevando ovolume de recursos destinados à saúde e que propunha várias re formas setoriais com ênfase na redução do papel do Estado - inicia um programa de pesquisa destinado aos países em desenvolvimento. Esforço que culmina na publicação pelo Banco Mundial do documento "Investindo em saúde".

Essa diversidade de ações empreendidas por outras agências internacionais ofuscou seriamente a liderança da OMS, colocando-a em um lugar politicamente instável e pouco estratégico frente às mudanças na ordem política e econômica mundial. Essa crise, que tomou dimensões estruturais, será tratada mais adiante.

\section{Funcionamento}

A Assembléia Mundial de Saúde é a principal instância de decisão da OMS e é realizada todo mês de maio. Dela fazem parte todas as 191 delegações dos países membros, distribuídos em seis escritórios regionais (Figura 1). Sua principal função é determinar a política da organização. A assembléia elege o diretor geral da OMS, supervisiona a política de financiamento e avalia e aprova a proposta do programa orçamentário. Da mesma forma, avalia e considera o relatório do grupo executivo para qualquer investigação, estudo ou ação que possa ser requerida. 


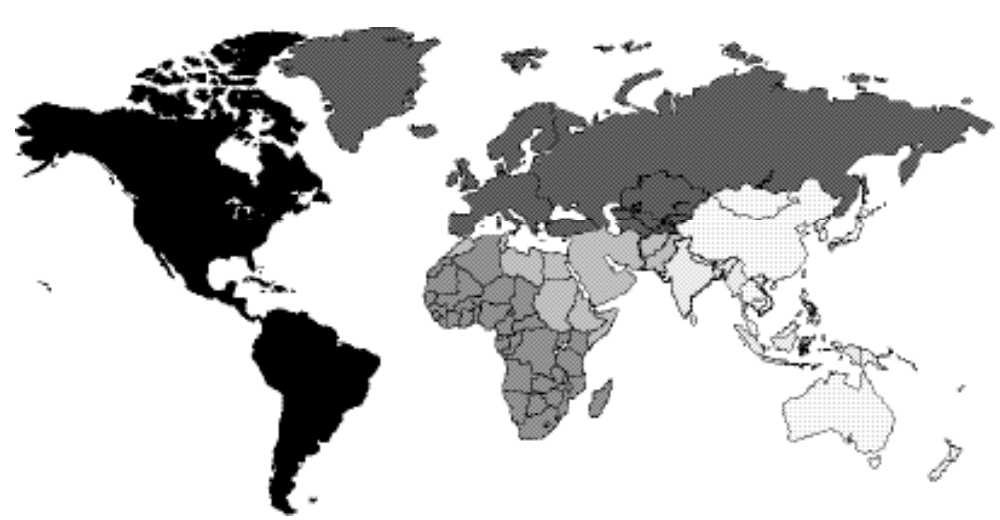

Opas - Organização Pan-Americana da Saúde (Washington DC, EUA)

Euro - Escritório Regional para a Europa (Copenhague, Dinamarca)

Afro - Escritório Regional para a África (Harare, Zimbábue)

Emro - Escritório Regional para o Mediterrâneo Oriental (Cairo, Egito)

Searo - Escritório Regional para o Sudoeste da Ásia (Nova Déli, Índia)

WPRO - Escritório Regional para o Pacífico Ocidental (Manila, Filipinas)

Fonte: WHO (World Health Organization). 2002a. History of WHO and International Cooperation in Public Health. Disponível em: <www.who.int/aboutwho/en/history.htm>. Acesso em: 20 abril 2002

O grupo executivo é composto por 32 me m brostecnicamente qualificados do campo da saúde, que são eleitos pelo período de três anos. As principais funções do grupo executivo são efetivar as decisões e políticas determinadas pela assembléia, instruí-la e, de forma geral, facilitar o seu trabalho.

O secretariado da OMS é formado por 3.500 especialistas da área de saúde e de outras áre as, marcando compromissos, trabalhando na sede ou nos seis escritórios regionais ou, ainda, nos países membros.

\section{Financiamento}

A OMS é financiada através de duas fontes diferentes de receita: uma receita regular, re p resentada pelas contribuições dos países membros e membros associados, e a receita proveniente de outras fontes 6 , representada pelas contribuições voluntárias ${ }^{7}$ de países membros e por outras fontes de doações e incentivos.

A Tabela 1 ap resenta a evolução orçamentária da OMS do biênio 19881999 ao 2000-2001 (WHO, 2002b). 
Tabela 1

\begin{tabular}{lccc}
\hline Evolução orçamentária bianual da OMS (1998-1999 e 2000-2001) & & \\
\hline Fontes orçamentárias & $\begin{array}{c}\text { 1998-1999 } \\
\text { (US\$ milhão) }\end{array}$ & $\begin{array}{c}\text { 2000-2001 } \\
\text { (US\$ milhão) }\end{array}$ & $\begin{array}{c}\text { Aumento } \\
\text { (\%) }\end{array}$ \\
\hline Receita & 1.800 & 2.300 & 28 \\
$\quad$ Para atividades de prog ramas da OMS & 2.200 & 2.700 & 23 \\
$\quad$ Total & & & \\
Despesas & 1.700 & 2.100 & 24 \\
Para atividades de prog ramas da OMS & 2.000 & 2.500 & 25 \\
Total & 843 & 843 & 0 \\
Recursos orçamentários (contribuições compulsórias) & 931 & 1.450 & 56 \\
Recursos extra-orçamentários (contribuições voluntárias) & 931 & \\
\hline
\end{tabular}

Fonte: WHO (World Health Organization). 2002c. Pro posed Prog ramme Budget 2002/2003. Disponível em: <www.who.int/gb/e/e_ppb2002.html>. Acesso em: 15 jan. 2005

Nota: Dados trabalhados pelo autor.

A Tabela 2 apresenta o Programa Orçamentário de 1998-1999 de recursos orçamentários e extra-orçamentários por região e níveis global/inter-regional.

Tabela 2

Recursos orçamentários e extra-orçamentários por área da OMS (1998-1999)

\begin{tabular}{lcccccc}
\hline Área & \multicolumn{2}{c}{$\begin{array}{c}\text { Recursos orçamentários } \\
\text { US\$ mil }\end{array}$} & $\%$ & \multicolumn{2}{c}{ Recursos extra-orçamentários } & \multicolumn{2}{c}{ Total } \\
& US\$ mil & $\%$ & US\$ mil & $\%$ \\
\hline África & 157.413 & 18,68 & 66.447 & 6,94 & 223.860 & 12,43 \\
Américas & 82.686 & 9,81 & 222.311 & 23,20 & 304.997 & 16,94 \\
Sudoeste da Ásia & 99.251 & 11,78 & 15.811 & 1,65 & 115.062 & 6,39 \\
Europa & 49.823 & 5,91 & 36.037 & 3,76 & 85.860 & 4,77 \\
Medite rrâneo Oriental & 90.249 & 10,71 & 6.905 & 0,72 & 97.154 & 5,40 \\
Pacífico Ocidental & 80.279 & 9,53 & 17.127 & 1,79 & 97.406 & 5,41 \\
Gobal/Inter-regional & 282.53 & 33,58 & 593.453 & 61,94 & 876.406 & 48,67 \\
Total & $\mathbf{8 4 2 . 6 5 4}$ & 100 & 958.091 & 100 & 1.800 .745 & 100 \\
\hline
\end{tabular}

Fonte: WHO (World Health Organization). 2000. Informe sobre la Salud en el Mundo 2000: mejorar el desempeño de los sistemas de salud. Disponível: <www.who.int/whr/2000/en/whr00_en.pdf>. Acesso em: 15 jul. 2002

As Tabelas 1 e 2 mostram claramente o crescimento dos re cursos extras e a dependência da OMS destes recursos para o desenvolvimento de suas atividades e o cumprimento do seu programa orçamentário. Isto é, a contribuição compulsória dos países me m b ros manteve-se estável nos últimos anos e o crescimento dos recursos extra-orçamentários aponta para a necessidade cada vez maior de a OMS captar recursos para o desenvolvimento de programas específicos. 


\section{Um passado 'glorioso', um futuro duvidoso}

Nos últimos cinqüenta anos, o mundo testemunhou o aumento na expectati va de vida provocado pelo desenvolvimento das ciências da saúde e pelo manejo de condições de vida para a promoção da saúde e prevenção de doenças. Em escala mundial, em 1955, a expectativade vida ao nascer era de 45 anos e, em 1995, de 65 anos. Estima-se que, em 2025, essa média cresça para 73 anos (Reid e Pearse, 2003).

A OMS teve uma importante participação nesses resultados, principalmente com ações de imunização e erradicação de doenças até então fatais, com a divulgação de protocolos e o treinamento de profissionais em todo o mundo e, também, com o apoio e orientação aos países membros em situação de exclusão social e tecnológica (WHO, 1998a).

Além da erradicação da varíola e do controle da poliomielite no mundo, talvez o momento mais influente politicamente da OMS no cenário internacional tenha ocorrido durante a Conferência de Alma-Ata sobre Cuidados Primários de Saúde, em 1978, que gerou, em 1979, a Declaração de Alma-Ata.

Alma-Ata ocorre durante a gestão de Halfden Mahler, um gestor hábil e diplomático que conseguiu transmitir a necessidade de se estabelecer um pacto mundial para a saúde, juntamente com outra agência da ONU, o Unicef. A estrutura do que seria proposto na conferência foi desenhada durante a $30^{a}$ Assembléia Mundial de Saúde, em 1977, e ap rovada por unanimidade pelos países me m b ros da OMS. Em 1978, em Alma-Ata, no Cazaquistão, antiga União Soviética, 134 países assinam um acordo, com a presença de representações de 67 organizações internacionais e não-governamentais, que tem como meta atingir um nível de saúde que permita a todos os cidadãos do mundo, até o ano 2000, uma vida social e economicamente produtiva. Este programa foi denominado Saúde para Todos no Ano 2000.

Nesse momento histórico para a saúde pública mundial, a OMS atinge o ap ogeu de sua influência internacional, convocando os sistemas de saúde em todo o mundo a redirecionarem sua política para a saúde como um direito humano, devendo ser construída por políticas sociais e econômicas que reduzam a desigualdade e que permitam a participação social.

"III) O desenvolvi imento econômico e social baseado numa ordem econômica internacional é de importância fundamental para a mais plena realização da meta de Saúde para Todos no Ano 2000 e para a redução da lacuna existente entre o estado de saúde dos países em desenvolvimento e o dos desenvolvidos. A promoção e a proteção da saúde dos povos é essencial para o contínuo desenvolvimento econômico e social e contribui para a melhor qualidade de vida e para a paz mundial.

IV) É direito e dever dos povos participar individual e coletiva mente no planejamento e na execução de seus cuidados de saúde" (WHO, 1978). 
A OMS tenta convencer a comunidade internacional de que a saúde é fundamental para o desenvolvimento econômico e social e, para isso, necessita de recursos, planejamento e orientação, esta subsidiada pela OMS.

Para muitos autores, a participação e a capacidade de trabalho de Mahler foram fundamentais para o sucesso de Alma-Ata e também para a ascensão da OMS no cenário internacional. "Sob seu novo diretor geral, Dr. Halfden Mahler, a OMS inicia sua maior mudança de orientação política, do enfoque restrito à doença para uma orientação ampla sobre as causas econômicas e sociais do adoecer" (Godlee, 1994b).

Mais que influir no direcionamento dos sistemas de saúde, a OMS determina as áreas de ação prioritárias do Saúde para Todos no Ano 2000, onde a ênfase na atenção primária em saúde seria a principal estratégia de transformação dos sistemas de saúde nacionais, principalmente nos países em desenvolvimento.

A OMS deixa a arena puramente técnica de uma agência especializada para influir na condução das políticas sociais, impor va lo res como direito à saúde, participação social, eqüidade no acesso aos recursos e, principalmente, a adoção de políticas que visam intervir nas desigualdades sociais e no fosso entre países ricos e pobres.

Não é acidentalmente que Alma-Ata ocorre em território soviético, em plena Guerra Fria, onde os gastos com armamentos e equipamentos bélicos re presentam boa parte do orçamento dos países desenvolvidos. A mensagem política é clara e a OMS e o Unicef são os anfitriões do evento. Nesta passagem da Declaração de Alma-Ata, há uma re ferência crítica muito clara sobre a corrida armamentista que ocorreu durante a Guerra Fria nas décadas de 1970 e 1980.

\footnotetext{
“Poder-se-á atingir nível aceitável de saúde para todos os povos do mundo até o ano 2000 mediante o melhor e mais completo uso dos recursos mundiais, dos quais uma parte considerável é atualmente gasta em armamento e conflitos militare s. Uma política legítima de independência, paz, distensão e desarmamen to pode e deve liberar recursos adicionais, que podem ser destinados a fins pacíficos e, em particular, à aceleração do desenvolvimento social e econômico, do qual os cuidados primários de saúde, como parte essencial, devem receber sua parcela apropriada" (WHO, 1978).
}

Nesta época, a OMS começou a sofrer pressões de indústrias, grupos econômicos e países membros. Alguns elementos fundamentais para o sucesso do Saúde para Todos foram duramente atacados, não por critérios técnicos, mas agora por pressões políticas e econômicas. Foi o que aconteceu, por exe mplo, com a determinação pela OMS das regras para substituição do leite materno, que foram duramente combatidas pelos Estados Unidos, e principal- 
mente pela luta que a OMS empreendeu, no início da década de 1980, a favor da distribuição de medicamentos essenciais e da auto-sustentação dos países em desenvolvimento em relação a esses itens.

“O segundo maior confronto seguiu-se ao lançamento do programa de medicamentos essenciais da OMS em 1977. O objetivo da OMS era estimular uma política de medicamentos mais racional baseada numa lista de medicamentos essenciais, e encorajar os países a desenvolver suas próprias habilidades para produção dos medicamentos que mais necessitam. A indústria farmacêutica era fortemente contra essa iniciativa; e em 1985, em protesto ao programa de medicamentos essenciais, os EUA contiveram suas contribuições ao orçamento regular da OMS. Naquele momento, os EUA detinham 11 das 18 maiores companhias farmacêuticas" (Godlee, 1994b).

Essas mudanças que a OMS realiza em seus objetivos e ações colocam uma nova arena de negociação. O que antes era discutido em comitês para a criação de consensos técnicos, agora, nesta nova perspectiva, é imperativa a necessidade de negociação política, econômica e ideológica.

A década de 1980 reservaum futuro não tão glorioso para a OMS devido a algumas contingências econômicas e políticas características da conjuntura da época, pela entrada de outras agências na disputa do mercado de idéias em saúde e pelas dificuldades de gerenciamento interno da OMS.

A proposta de Saúde para Todos era abrangente demais para uma agência especializada das Nações Unidas. Apesar da aliança com o Unicef, muitas ações deliberadas em Alma-Ata dependiam de políticas, pactos sociais e econômicos que iam muito além das possibilidades de ação da OMS naquele momento.

Críticos apontam para a falibilidade do Saúde para Todos e para a incapacidade da OMS, perante suas dificuldades atuais, em conduzir esse processo. A OMS justifica a dificuldade em implantar o Saúde para Todos como uma conseqüência da conjuntura política e econômica internacional, a partir da instabilidade política de alguns países, da má utilização dos recursos financeiros e humanos e do precário desenvolvimento socioeconômico na maioria dos países pobres. Além disso, a OMS aponta para a manutenção da desvalorização da mulher na sociedade (WHO, 1998a).

A incapacidade ge rencial dos países pobres e em desenvolvimento no estabelecimento de prioridades, na gerência dos recursos, na captação de inve st imentos internacionais, e a precariedade da gestão público/privado nos sistemas nacionais de saúde são obstáculos estratégicos importantes para o estabelecimento do Saúde para Todos, segundo a OMS.

Ou seja, o não cumprimento das metas propostas em Alma-Ata não foi resultante da incapacidade gerencial da OMS em monitorar o processo, estimular pactos e apoiar e orientar os países em ações estratégicas, mas, sim, 
da complexidade da conjuntura política e econômica da década de 1980 e da incompetência dos sistemas nacionais de saúde em conduzir, adaptar e aplicar as orientações de Alma-Ata.

Para a OMS, Alma-Ata é um ícone de sucesso e fracasso simultaneamente. Sucesso por conta de um passado influente, quando era capaz de reunir a maioria dos estados nacionais, conduzir propostas, influir no desenho dos sistemas de saúde e nas políticas econômicas e sociais. E fracasso por ser uma meta jamais alcançada, uma proposta que se pulverizou com a mesma velocidade de seu surgimento, um descrédito de uma ação ambiciosa e uma data jamais cumprida. E também pela incapacidade de gerenciar processos de negociação política e econômica internacionais e no interior dos estados nacionais e pelo recuo frente às pressões de grandes interesses econômicos do mundo capitalista.

É inegável o marco da Declaração de Alma-Ata para as estratégias de promoção à saúde, para a defesa da saúde como direito e para uma concepção ampliada de saúde em todo o mundo. Mas o projeto Saúde para Todos no Ano 2000 representa, para muitos autores, uma bela e ingênua intenção de uma antiga agência especializada das Nações Unidas.

\section{Mudança ou morte}

Este é o título do editorial do British Journal of Medicine (Smith, 1995), que, ao lado do The Lancet, publicou durante a década de 1990 uma série de artigos sobre a OMS e sua perda de liderança no cenário internacional, bem como a necessidade de sua reestruturação e renovação política e administrativa.

Com o término da gestão de Mahler, houve também o abalo da liderança da OMS na saúde internacional. Em 1988, o Dr. Hiroshi Nakajima assumiu a direção geral da OMS e, com ele, o desenho político e social empreendido pelo seu predecessor foi substituído por uma gestão centrada na tecnocracia, no retorno a ações centradas na doença e no recuo dos grandes debates contra os interesses dominantes da indústria da saúde. O estilo imposto por Nakajima era conciliador e, portanto, apaziguador e por vezes omisso frente às grandes questões políticas e econômicas vigentes no final da década de 1980.

“Quando o Dr. Hiroshi Nakajima assumiu a direção geral em 1988, temia-se a fa lta de visão e liderança na condução desses debates. Como diretor da Região do Pacífico Oriental, foi responsável pelo sucesso da reabilitação do programa da OMS no Vietnam após a liberação de Saigon e por introduzir a OMS na China, à frente de todas as demais agências da ONU. Mas era conhecido por preferir formar compromissos do que produzir conflitos, e observad ores temiam que como diretor 
geral retirasse a OMS das controvérsias internacionais, retornando para as águas tranqüilas dos consensos médico-tecnológicos" (Godlee, 1994b).

A partir dessa gestão,questões como a oferta de medicamentos essenciais e a crítica tanto à privatização da saúde quanto à ênfase na atenção terciária tornaram-se distantes dos embates promovidos pela OMS.

Analisando as dificuldades da OMS durante a década de 1990, Godlee comenta:

“Após 15 anos sob a direção do visionário e carismático Dr. Halfden Mahler, membros da OMS e doadores estavam desapontados com o Dr. Hiroshi Nakajima, a quem viam como reservado e um comunicador com poucos recursos. Atualmente, pessoas de fora da OMS temem que com a sua direção a OMS esteja perdendo terreno para outras agências. Elas vêem a OMS se afastando da política de alta performance do Dr. Mahler, a qual fez da OMS uma influente defensora da eqüidade internacional e do uso racional dos recursos, retornando para as tradicionais confecções de protocolos e orientações técnicas sobre assuntos médicos" (Godlee, 1994a, p. 1.430).

O golpe político mais violento sofrido pela OMS, e que expôs sua frag ilidade ao mundo, foi a retirada do controle exclusi vodo Programa Global de Aids pela ONU, dividindo com o Programa das Nações Unidas para o Desenvolvimento (Pnud) e com o Fundo Populacional das Nações Unidas um orçamento anual de US\$ 164 milhões. Suas ações ficaram restritas às consultorias médicas, enquanto as ações de controle e prevenção ficaram a cargo das demais agências.

Aos poucos, outras agências foram surgindo no cenário internacional com políticas voltadas para a saúde, intervindo e prescrevendo diretrizes para os sistemas nacionais de saúde. O Unicef e o Banco Mundial começam a disputar a liderança de um campo que era domínio exclusivo da OMS.

Dois momentos fundamentais marcaram a entrada do Unicef e do Banco Mundial na disputa pelo domínio das estratégias mundiais de saúde. $\mathrm{O}$ primeiro, citado anteriormente, foi o distanciamento do Unicef das propostas abrangentes do Saúde para To d os, optando por ações isoladas através de programas de intervenção verticais para a redução da mortalidade infantil e a imunização. Essas ações receberam apoio de poderosas organizações internacionais, como o Banco Mundial, contratando profissionais, capacitando recursos humanos e fornecendo insumos. O segundo foi a divulgação do Relatório do Desenvolvimento Mundial de 1993, conhecido como "Investindo em saúde". As teses expressas pelo relatório propunham ajustes econômicos estruturais, o financiamento da atenção à saúde pelo capital privado e uma crítica contundente à universalidade do acesso à saúde 8 . 
"Sob outras circunstâncias, dizoPro fessor Nath, decano do Instituto de Ciências Médicas da Índia, a OMS teria discutido e até criticado as conclusões desses relatórios. Sua ênfase em orientações técnicas tem pre venido a organização de uma postura mais combativa. 'A OMS era a última corte de apelação quando o assunto era saúde', diz ele. 'O Banco Mundial tem retirado essa iniciativa da OMS em assuntos de saúde. Há alguns anos isso seria inconcebível'" (Godlee, 1994b).

Nesse sentido, diversos observa d o res do campo da saúde internacional afirmam que, em gestões anteriore s, como a de Mahler, a OMS teria reagido veementemente às propostas do Banco Mundial.

\section{A crise}

Com a gestão de Nakajima e os acontecimentos nas políticas internacionais de saúde, a OMS se depara com uma crise sem precedentes. Uma crise não apenas política, mas principalmente de identidade.

Da década de 1990 em diante, encontram-se diversos artigos, editoriais e cartas de leitore s, em revistas como The Lancet, British Medical Journal e outras, comentando em tom de denúncia uma crise política e econômica na OMS. Esses argumentos apontam para a falta de objetivo s, o excesso de burocracia e até mesmo a existência de ações corruptas no interior da agência. "A agência sediada em Genebra, a qual celebrou seu $50^{\circ}$ aniversário, foi criticada por ser muito 'pesada', lenta, demasiadamente politizada, até corrupta, e com uma burocracia que a torna incapaz de responder à velocidade dos desafios da saúde internacional" (McCarthy, 2002).

O que é importante destacar é a repercussão da necessidade de reestruturação da OMS frente à opinião pública, abalando negativamente sua credibilidade no cenário político internacional. Essa 'crise' política faz com que a OMS reveja seus objetivos, sua metodologia, sua relação com os países me mbros e, principalmente, lute para tentar retomar a liderança no mercado de idéias sobre saúde em âmbito mundial.

\section{Ofertar idéias ou implementar programas?}

Há uma discussão estratégica no interior da OMS, e também entre críticos atentos às suas ações, aos seus gastos e às suas metodologias, que contempla duas questões centrais: para que serve a OMS e como ela deve agir.

Neste sentido, uma agência como a OMS deve normatizar ações e políticas de saúde em todo o mundo, ofe recer manuais de orientações e protoco- 
los, assessorar os países me m b ros na condução de políticas e programas de saúde? Ou deve implementar ações, intervir no combate a doenças e desigualdades que afetam o estado de saúde das populações?

“Um debate permanente é sobre o quanto a OMS deve ser predominantemente uma agência normativa, estabelecendo padrões, desenvolvendo protocolos e provendo informações que podem ser utilizadas pelos governos e agências quando implementam seus próprios programas - ou o quanto a OMS deve também estar envolvida nas implementações de seus próprios programas" (McCarthy, 2002).

Essa não é apenas uma discussão política, mas também econômica, no sentido de que se trata do uso dos recursos investidos pelos países membros na OMS e o retorno desses investimentos em termos da resolutividade de determinados problemas sanitários.

Algumas repercussões podem ser observadas em relação ao direcionamento de ações produzidas pela OMS, como, por exemplo, o crescimento da receita extra-orçamentária (extra-budget). Nos últimos vinte anos, a receita regular(regular-budget) da OMS, que compreende a contribuição anual dos países membros, baseada em critérios populacionais e renda, não aumentou (gráfico 1). Devido à crise inflacionária da década de 1980 e às prioridades políticas e econômicas de diversos países, essa receita estacionou e foi corroída pela inflação, mas os próprios países me $\mathrm{m}$ b ros e outras instituições começ aram a investir re cu rsos extra-orçamentários em programas específicos como Aids, malária e outros.

\section{Gráfico 1}

Variação da re ceita regular da OMS por biênio (1976-1994)

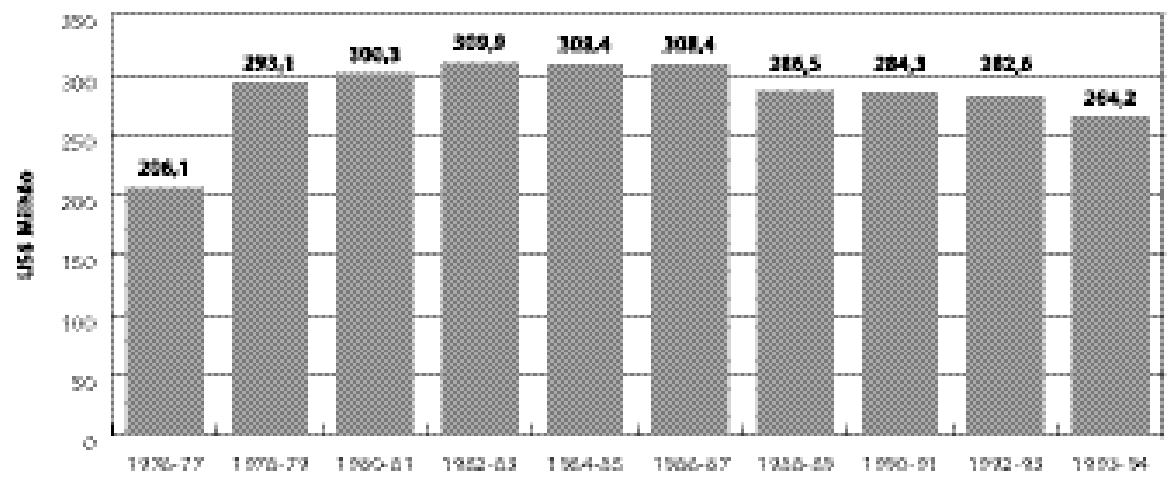

Fonte: GODLEE, Fiona. 1994a. The Wo rld Health Organization:WHO in crisis. British Journal of Medicine, n. 309, p. 1.429 
Com esta mudança de comportamento, a OMS perde sua capacidade de coordenação política e cada programa passa a ser um 'produto' em um mercado doméstico, interno à própria OMS. Era necessário rever os objetivos, conquistar credibilidade, reaver investimentos, mostrar claramente ao mundo que a OMS está atenta à nova ordem mundial, trabalhando com áreas prioritárias, e que sabe pensar e agir globalmente.

É nesse contexto de uma OMS também ofuscada pela oferta de idéias do Banco Mundial e pela articulação de recursos voltados para a saúde feita pelo Banco Mundial e Unicef que Gro Harlem Brundtland assume, tentando levar a OMS a resgatar sua hegemonia.

\section{A gestão Gro Harlem Brundtland}

Tomada como uma organização tradicional, pesada administrativa mente e ineficiente, a OMS também recebia críticas por não acompanhar a mudança da relação entre os gêneros, especialmente quanto à ausência de mulheres em seu corpo diretor. Em 1998, a norueguesa Gro Brundtland, ex-primeira-ministra da Noruega, assume a direção geral da OMS com a responsabilidade de reestruturar e mostrar ao mundo que a organização está viva e apta a reaver o seu lugar na liderança do cenário sanitário internacional. “Uma mulher foi encarregada de salvar a organização. Gro Harlem Brundtland assumiu como diretora-geral em 21 de julho de 1998 e prometeu uma reforma radical na OMS" (Yamey, 2002, p. 1.107). Sua posse é marcada por pro messas de mudanças na política interna e externa na OMS e pelo apoio de organizações como a Fundação Rockefeller.

“A Fundação Rockfeller aportará um fundo de US\$ 2,5 milhões para que possa contratar especialistas de alto nível de fora da OMS, que funcionem como assessores durante o próximo período de transição de um ou dois anos. Assim estará livre para escolher entre as pessoas mais talentosas do mundo" (WHO, 1998b, p. 286).

Ao realizar seu discurso na $51^{\text {a }}$ Assembléia Mundial de Saúde, Brundtland, antes de tomar posse, anuncia algumas diretrizes da sua gestão e a necessidade de influir e orientar os países membros em suas políticas e ações.

“Na reorganização — a qual pretendo implementar desde o primeiro dia —, priorizarei quatro áreas de interesse:

- A OMS ajudará a monitorar, minimizar e, quando possível, erradicar doenças comunicáveis.

- A OMS ajudará a lutar e reduzir a carga de doenças não-comunicáveis. 
- A OMS ajudará os países a construir sistemas de saúde sustentáveis que possam fortalecer as metas de eqüidade e promover qualidade nos serviços para todos, com uma ênfase particular sobre a situação crítica de mulheres e mães que garantam um parto seguro e um início de vida saudável.

- A OMS orientará os assuntos relacionados à saúde, voltando-se para evidências sólidas e, através disso, melhor advogar sobre tomadas de decisão em políticas de saúde em todo o mundo" (Brundtland, 1998).

O recado é rápido, mas certeiro. Brundtland anuncia para a comunidade dos países me mbros que compõem a Assembléia Mundial de Saúde que a nova gestão terá prioridades e voltará a exercer sua liderança técnica e política sobre a oferta de idéias para os sistemas nacionais de saúde. Para isso, já anuncia sua preocupação em avaliar, a partir de instrumentos que aferem a carga da doença, o impacto dos estilos de vida e dos contextos socioeconômicos e ambientais sobre a saúde das populações.

Um outro comunicado breve, mas contundente, para a organização interna da OMS diz respeito à re organização dorelacionamento com os seus escritórios regionais, bem como a crítica da repartição entre receita regular e receita extra-orçamentária.

"Para ter sucesso nesse desafio, nós devemos estar aptos a dizer: A OMS é uma. Não são duas - no sentido de um financiamento da receita regular e outro dos fundosextra-orçamentários.Não são sete - no sentido de Genebra e os seis escritórios regionais. Não mais que 15 - no sentido dos programas individuais" (Brundtland, 1998, grifo do autor) ${ }^{9}$.

A então futura diretora da OMS também anuncia que a agência estará atenta à nova ordem mundial, identificando avanços e desafios para a saúde no mundo globalizado.

"A globalização está possibilitando novas oportunidades de crescimento e progresso. Mas seus benefícios não são distribuídos adequadamente. A globalização tem trazido novas e críticas ameaças para a saúde e o ambiente. (...) O mundo está em transição. Conseqüentemente, a OMS deve estar em transição. Olhando adiante" (Brundtland, 1998).

O discurso é muito rico em alusões a respeito da necessidade de mudança, reestruturação, união e, principalmente, da necessidade de se estabelecer prioridades. Prioridades de ações e programas, prioridades nas relações e apoio aos países membros, principalmente aos mais pobres, prioridade nas ações contra o fumo e contra a malária. Estas deverão ser objetos de uma 
base sólida de evidências científicas. Baseada na noção de carga de doença, a gestão Brundtland avaliará os diversos sistemas de saúde, propondo, a partir dessas evidências construídas com o uso de indicadores compostos e transculturais, estratégias e ações para o desenvolvimento da saúde no mundo.

\section{O polêmico relatório de 2000}

Durante a década de 1990, principalmente durante a gestão de Gro Harlem Brundtland, a OMS realiza uma 'megaoperação' para avaliar os sistemas de saúde em todo o mundo. O resultado pode ser observado no Relatório Mundial de Saúde de 2000, intitulado "Sistemas de saúde: melhorando a performance".

Esta política é ap resentada como a missão da OMS para empreender o maior nível possível de saúde, fundamentado em um dos seus princípios constitucionais, com o objetivo de reduzir as desigualdades em cada país e entre eles. "A habilidade da organização em cumprir sua missão depende em grande parte da efetividade dos sistemas de saúde dos países membros - e fortalecer esses sistemas é uma das quatro determinações estratégicas da OMS" (WHO, 2000).

Além de avaliar, a OMS organizou um índex dos sistemas de saúde de cada país, classificando-os de acordo com o escore de suas performances. Para a OMS, essa classificação auxiliaria os países me $\mathrm{m}$ bros a avaliar seus próprios sistemas, contribuindo para sua melhoria e para perceber as necessidades de sua população. “Formuladores de políticas necessitam saber por que os sistemas de saúde obtêm determinados desempenhos e o que podem fazem para melhorar a situação" (WHO, 2000).

Para a realização do trabalho, Gro trouxe especialistas da Universidade de Harward e do Banco Mundial, formando um forte grupo de pesquisa para a construção de evidências. Ao longo de sua gestão, este grupo publicou dive rsos trabalhos e exerceu sua influência para o uso de instrumentos multidimensionais enfocando a vida como um valor relacionado à saúde (Ya mey, 2002).

Com o ingresso dos especialistas de Harva rd e do Banco Mundial10, a OMS parecia iniciar um modelo político que se assemelhava ao realizado pelo Banco Mundial. Ou seja, avaliando sistemas de saúde, criando demandas e colocando-se como autoridade técnica e política para orientar e conduzir os processos de saúde globais.

Esse relatório causou enorme polêmica entre os países membros da OMS, questionando-se os interesses da OMS em realizar um estudo dessa natureza, que não só avalia, mas também compara os diversos sistemas de saúde, cuja metodologia e cujos instrumentos utilizados, além do distanciamento do estudo das realidades sociais, culturais e políticas nacionais, foram durame n- 
te criticados. "Avaliar sistemas de saúde não é tarefa simples, principalmente quando o objetivo é comparar realidades distintas, como os sistemas dos países membros, e a recente contribuição da OMS é bastante criticável" (Travassos e Buss, 2000, p. 890).

Entre os objetivos desse trabalho, destacam-se três que fundamentaram sua metodologia: 1) melhoria do estado de saúde da população, reduzindo as desigualdades; 2) aumento da capacidade de resposta à expectativa da população; 3) assegurar a eqüidade na distribuição dos recursos financeiros.

Esse novo perfil político da OMS na sua relação com seus países memb ros procura ressituar sua influência no contexto sanitário internacional, principalmente a partir da construção de indicadores e da análise e comparação dos sistemas de saúde nacionais. Os indicadores são utilizados a partir da premissa de que o objeto a ser avaliado é a qualidade de vida da população, analisando as dimensões da vida que contribuem para o processo saúde-doença. Essa política permite que a OMS opine não apenas no setor saúde, mas também sobre as políticas socioeconômicas de uma nação, do mesmo modo que o Banco Mundial o fez com o "Investindo em saúde", constituindo sua estratégia de hegemonia atual.

\footnotetext{
"Qual a nossa principal missão? Eu vejo a OMS como sendo a voz moral e o líder técnico no desenvolvimento da saúde das pessoas no mundo. Pronta e apta a dar orientação sobre assuntos-chave que podem desencadear o desenvolvimento e minimizar o sofrimento. Eu vejo que nossa proposta é combater a doença e o malestar - promovendo sistemas de saúde sustentáveis e equânimes em todos os países" (Brundtland, 1998).
}

\section{Reforma administrativo-financei ira ou política?}

O aumento dos recursos extra-orçamentários, segundo a diretora-geral da OMS, deve-se ao início de uma reformulação administrativa, financeira e política da instituição. Nessa reformulação administrativa, os países doadores solicitam maior controle sobre a destinação dos re c u rsos em programas específicos, em vez de destiná-los à estrutura da OMS. Estas mudanças culminaram no que se denominou Determinações Estratégicas. Estas determinações foram elaboradas pelo grupo executivo, em 2000, e apresentam quatro aspectos básicos, que se inter-relacionam (WHO, 2002c):

- Redução do excesso de mortalidade, morbidade e incapacidade, especialmente em populações pobres e marginalizadas;

- Promoção de estilos de vida saudáveis e redução dos fatores de risco para a saúde humana que se originam de causas comportamentais, sociais, econômicas e ambientais; 
- Desenvolvimento de sistemas de saúde que aperfeiçoem com eqüidade os indicadores de saúde, respondendo às legítimas demandas populares e financeiramente viáveis; $\mathrm{e}$

- Estruturação de uma política empreendedora e criação de um ambiente institucional para o setor saúde, prom ovendo uma efetiva política de saúde para as dimensões sociais, econômicas, ambientais e desenvolvimentistas.

Essas determinações deverão ser aplicadas a cada uma das 35 áreas de concentração da OMS, sendo que 11 destas áreas terão prioridade. Estas prioridades foram escolhidas pelo grupo executivo a partir da avaliação dos principais problemas de saúde do mundo, com ênfase nas iniqüidades sanitárias entre os países e dentro deles, na maior efetividade, na necessidade urgente de novas tecnologias, na necessidade da construção de consensos e políticas e na maior demanda de suporte aos países membros. As 11 áreas prioritárias são: malária; tuberculose; HIV/Aids; câncer, doenças card iova scula rese diabetes; tabaco; saúde materna; desnutrição; saúde mental; segurança no sangue; sistemas de saúde; e investindo em mudanças na OMS.

As determinações estratégicas, tendo em vista a atuação da OMS nestas áreas específicas, orientam o programa orçamentário, determinando o investimento dos recursos em cada região ou programa.

Não foram apenas as determinações estratégicas que estabeleceram prioridades e novas relações com os países membros. Durante a gestão de Brundtland, novas relações institucionais foram empreendidas pela OMS para o desenvolvimento de ações que trouxessem investimentos e fortalecessem sua capacidade de influir politicamente em um mundo globalizado.

A parceria com instituições privadas, como indústrias farmacêuticas, e com a Organização Mundial do Comércio (OMC) foi alvo de críticas na ge stão Gro Brundtland.

\footnotetext{
“O setor privado tem uma importante participação no desenvolvi mento tecnológico e na provisão de serviços. Nós precisamos de relações abertas e construtiva s com o setor privado e a indústria, reconhecendo quando nossos objetivos divergem e quando se complementam. Convido a indústria a juntar-se a nós num diálogo sobre os principais assuntos que nos aproximam" (Brundtland, 1998).

"Consideramos essa união entre a OMS e o secretariado da Organização Mundial do Comércio uma iniciativa útil e oportuna (...). Ela ilustra que existe um solo comum entre comércio e saúde" (WTO/WHO, 2002).
}

No site da OMS, é possível encontrar mais de 70 parcerias com instituições, principalmente fundações, que participam de várias formas em programas e ações da OMS. 
“A página na Internet da OMS sobre Parceria Público-Privado para a Saúde identifica atualmente 79 colab or ações. Anatureza e proposta dessas parcerias va ria m bastante. Algumas têm sido criadas para o desenvolvimento de produtos (incluindo vacinas), outras para distribuição de produtos subsidiados (como medicamentos para HIV/Aids), outras para propostas de educação em saúde, para o desenvolvimento do controle de qualidade de produtos, e outras, de forma mais genérica, para coordenação de sistemas de saúde" (Reid e Pearse, 2003, p. 10-11).

A gestão de Brundtland é apontada pela maioria dos autores como uma gestão que trouxe a OMS de volta ao debate da saúde internacional. Apesar de curto, seu mandato deu um direcionamento à desacreditada agência da ONU, conquistou a confiança da comunidade internacional de doadores e, acima de tudo, colocou na agenda da OMS a necessidade do ajuste político e estrutural para acompanhar as transformações de um mundo globalizado.

\section{Considerações finais}

As transformações institucionais ocorridas na OMS durante a gestão Brundtland acontecem numa época em que diversas agências internacionais começam a voltar seu interesse para a saúde e grandes volumes derecursos passam a transitar pelo mundo para se investir em saúde. Esse movi mento tem sido chamado por alguns autores de Global Health11, período em que pod e rosas organizações não-governamentais, fundações, agências internacionais e, até mesmo, departamentos de saúde de países desenvolvidos começaram a se interessar pela saúde das populações de países pobres.

O movi mento técnico-político sintetizado na noção de Global Health, iniciado na década de 1990, tem procurado relacionar as transformações do mundo globalizado e suas repercussões para a saúde do mundo e de cada país. São instituições governamentais como o Office of Global Health, do Departamento de Saúde e Serviços Humanos do governo norte-americano; instituições acadêmicas como a Universidade de Pittsburgh, nos Estados Unidos; organizações não-governamentais, como o Global Health Council; programas de grandes organizações e corporações econômicas, como o Global Health Initiative do Fórum Econômico Mundial; programas e políticas de agências internacionais como a OMS, o Banco Mundial e o Unicef.

O alinhamento da agenda da saúde com as estratégias de globalização econômica, cultural e científica parece ter norteado essa nova arena de negociação política denominada Global Health. Ao mesmo tempo em que algumas transformações provocadas pela transnacionalização da economia e a revolução proporcionada pelas tecnologias da informação e da comunicação produziram novos desafios para o mundo, incluir o adjetivo 'global' nas po- 
líticas e práticas institucionais transmite a idéia de que se está atento e alinhado com a nova ordem mundial e, conseqüentemente, com as práticas lingüísticas contemporâneas.

Para além do seu uso retórico,ofenômeno político Global Health representa não apenas uma mudança de nomenclatura, mas também a construção de uma nova agenda para a saúde do mundo. As lutas e discussões sobre política de saúde internacional deixam o território ge ográfico de países e regiões e procuram impor uma 'transterritorialidade' às demandas, às avaliações e aos procedimentos, excluindo as especificidades sociais, econômicas, políticas e culturais dos estados nacionais e suas complexidades. Discussões sobre atenção primária, controle de doenças e avaliação de sistemas de saúde passam a constituir um painel para o planejamento de ações globais, baseado na interdependência econômica e tecnológica dos estados nacionais.

A OMS entra nessa corrida por inve stimento e pela hegemonia técnica e política sobre o mercado da saúde global. Com isso, há um mov i mento nas políticas das agências internacionais de saúde na constituição de políticas globais, isto é, avaliações transculturais, conceitos universais e traduzíveis em diversas culturas, em uma uniformização dos métodos de avaliação, das necessidades e das políticas. Pensar globalmente, planejar globalmente e avaliar globalmente têm sido práticas comuns para a criação de padrões de evidências empíricas observáveis globalmente, estabelecendo comparações, ranqueando sistemas de saúde, avaliando e padronizando procedimentos em todo o mundo.

É nesse esforço de construção de indicadores e políticas afinadas com as estratégias de saúde globais em sua perspectiva hegemônica que a OMS concentrará suas ações durante o final da década de 1990, tentando posicionar-se nesse novo espaço de luta política no campo da saúde internacional, atravessado pelos interesses econômicos e culturais instituídos pelos processos de globalização. 


\section{Notas}

1 Pesquisador visitante (Paetec/Faperj) da Escola Politécnica de Saúde Joaquim Venâncio, da Fundação Oswaldo Cruz (EPSJV/Fiocruz). Doutor em Saúde Coletiva pelo Instituto de Medicina Social da Universidade do Estado do Rio de Janeiro (IMS/Uerj). <gcmatta@fiocruz.br>

2 Este trabalho é uma ve rsão de parte da tese de doutorado, na qual foi investigada a criação do instrumento de avaliação de qualidade de vida da OMS, conhecido como WHOQOL, e suas relações com a formulação de políticas de saúde globais (Matta, 2005).

3 Um editorial do The Lancet chegou a afirmar que o Banco Mundial teria assumido a liderança no que tange à saúde internacional que antes era da OMS. O Banco Mundial publicou o "Relatório do Desenvolvimento Mundial de 1993: Investindo em Saúde", que suge re a utilização de medidas do impacto da doença e a adoção de políticas nacionais de saúde para a melhoria do estado de saúde no mundo, principalmente nos países em desenvolvimento. Ver Mattos (2000 e 2001).

4 Todos os textos e as expressões em inglês presentes ao longo do trabalho foram traduzidos livremente pelo autor.

5 He gemonia é aqui entendida tal como descrito por Luz (1986, p. 29): “(..) Gramsci elabora o conceito de hegemonia, poder político-ideológico que a classe dominante pro cura estender ao conjunto da sociedade, à totalidade das classes e aos grupos sociais. Procuramos ter deste conceito uma interpretação dinâmica, vendo a hegemonia, em prime i ro lugar, como processo, como prática sempre recomeçada e, em segundo luga r, como prática contraditória, na medida em que institui como universal uma Ordem que é fundamentalmente particular".

6 Também chamadas de fontes extra-orçamentárias.

7 Essas contribuições geralmente são feitas através das agências nacionais voltadas para a ajuda internacional. Parte dos recursos dessas agências é destinada a programas específicos coordenados por alguma agência e/ou fundo do sistema das Nações Unidas. Essa dinâmica de doação cria uma certa competição entre agências especializadas desse sistema pela captação desses recursos.

8 Um estudo detalhado sobre as propostas do Banco Mundial na área de saúde e, em especial, o "Investindo em Saúde" foi realizado por Mattos (2000).

9 O gri fo está no original. Como é um discurs o, o texto original ap resenta algumas palavras e expressões para serem enfatizadas oralmente.

10 Uma observação oportuna é que Christopher Murray, diretor do Programa Global sobreEvidência para Saúde Pública da OMS, participou também do desenvolvimento da metodologia do Investindo em Saúde do Banco Mundial.

11 Optamos por manter o original em inglês por acreditar que a tradução 'saúde global' reduziria o alcance político pretendido pelas agências e instituições envolvidas. Para uma discussão mais detalhada sobre Global Health, ver Matta, 2005. 


\section{Referências}

BRIGHAM YOUNG UNIVERSITY. 2005. What is Global Health? Disponível em: $<$ mph.byu.edu/faq/index.php $>$. Acesso em: 28 jan. 2005.

BROW N, Theodore M.; CUETO, Marcos; FEE, Elizabeth et al. 2005. The World Health Organization and the transition from "international" to "Global" Public Health. Disponível em: <www.globalhealthtrust.org/doc/abstracts/WGl/ FeeBrownCuetoPAPER.pdf $>$. Acesso em: 28 jan. 2005.

BRUNDTLAND, Gro H. 1998. Acceptance speech for the World Health Assembly, 13 May 1998. Disponível em: <www. who.int/director-general/biographies/ gh_ brundtland.en.html>. Acesso em: 15 jul. 2002.

BULLINGER, Monika. 2003. International comparability of health interview surveys: an overview of methods and approaches. In: NASIKOV, Anatoliy.; GUDEX, C. (Eds.). EUROHIS: developing common instruments for health surveys. Amsterdam: IOS Press, p. 61-77.

CASTELLS, Manuel. 1999. A sociedade em rede. São Paulo: Paz e Terra. (A era da informação: economia, sociedade e cultura; v. 1).

FIORI, José Luís. 1995. Em busca do dissenso perdido: ensaios críticos sobre a festejada crise do Estado. Rio de Janeiro: Insight.

FOUCAULT, Michel. 1979. Microfísica do poder. Rio de Janeiro: Graal.

GL O BAL HEALTH CONCIL. 2005. Who we are. Disponível em: <www.globalhealth. org/>. Acesso em 30 jan. 2005.

GODLEE, Fiona. 1994a. The World Health Organization: WHO in crisis. British Journal of Medicine, n. 309, p. 1.4241.428 .

.1994 b. WHO in re treat: is it losing its influence? British Journal of Medicine, v. 309, n. 6967, p. 1491-1495. Disponível em: <bmj.bmjjournals.com/cgi/ content/ full/309/6967/1491>. Acesso em: 15 jan. 2005.

1995. The World Health Organisation: interview with the director general.
British Journal of Medicine, n. 310, p. 583-588.

IOM (Institute of Medicine). 1997. America's vital interest in Global Health: protecting our people, enhancing our economy, and advancing our international interests. Washington: National Academy Press. Disponível em: <www.nap.edu/ readingroom/books/avi/>. Acesso em: 24 jan. 2005.

LEE, Kelley. 1998. Shaping the future of global health cooperation: where can we go from here? The Lancet, v. 351, p. 899-902.

LIMA, Nísia T. 2002. O Brasil e a Organização Pan-Americana da Saúde: uma história em três dimensões. In: FINKELMAN, Jacobo (org.). Caminhos da Saúde Pública no Brasil. Rio de Janeiro. Ed. Fiocruz, p. 23-116.

LUZ, Madel Therezinha. 1986. As instituições médicas no Brasil: instituição e estratégia de hegemonia. $3^{\text {a }}$ ed. Rio de Janeiro: Edições Graal.

MATTA, Gustavo C. 2005. A medida politica da vida: a invenção do WHOQOL e a construção de políticas de saúde globais. Tese de Doutorado, Rio de Janeiro: Instituto de Medicina Social, Unive rs idade do Estado do Rio de Janeiro.

MATTOS, Ruben A. de. 2000. Desenvolven do e ofertando idéias: um estudo sobre a elaboração de propostas de políticas de saúde no âmbito de Banco Mundial. Tese de Doutorado, Rio de Janeiro. Instituto de Medicina Social, Universidade do Estado do Rio de Janeiro. .2001 As agências internacionais e as políticas de saúde nos anos 90: um panorama geral da oferta de idéias. Ciência \& Saúde Coletiva, v. 6, n. 2, p. 377-389.

MCCARTHY, Michael. 2002. What's going on at the World Health Organization? The Lancet, v. 360, n. 9.340. Disponível em: $<$ www.thelancet.com/journals/lancet/ section ? volume $=360 \&$ issue $=9340 \&$ sec tion $=$ Special + Report $>$. Acesso em: 15 jan. 2005.

MINAYO, Maria Cecília de S. et al. 2000. Qualidade de vida e saúde: um debate 
necessário. Ciência \& Saúde Coletiva, v. 5, n. 1, p. 7-18.

MORAES, Ilara H. S. de. 1998. Informação em saúde: para andarilhos e argonautas de uma tecnodemocracia emancipadora. Tese de Doutorado, Rio de Janeiro: Escola Nacional de Saúde Pública, Fundação Oswaldo Cruz.

2002. Política, tecnologia e informação em saúde. Salvador: Casa da Qualidade Editora.

MURRAY, Christopher J. L.; SALOMON, Joshua A.; MATHERS, Colin de. 2002. A critical examination of summary measures of population health. In: MURRAY, Christopher J. L. (ed.). Summary measures of population health: concepts, ethics, measure ment and applications. Genebra: WHO, p. 13-40.

NASIKOV, Anatoliy; GUDEX, C. 2003. Overview of the EUROHIS project. In: NASIKOV, Anatoliy; GUDEX, C. (eds.). EURO HIS: developing common instruments for health survey s. Amsterdam: IOS Press, p. 13-20.

PERELMAN, Chaim. 1999. Retóricas. São Paulo: Martins Fontes.

: OLBRECHTS-TYTECA, Lucie. 2000. Tratado da argumentação: a nova retórica. São Paulo: Martins Fontes.

PHM (People's Health Movement). 2000. Asamblea de la Salud de los Pueblos (ASP): salud en la era de la globalización — de víctimas a protagonistas. Disponível em: <www.phmovement.org/pdf/ pha2000/spanish/phm-pha-frameworkspanish.pdf>. Acesso em: 30 jan. 2005.

REID, Michael A.; PEARSE, E. Jim. 2003. Whither the World Health Organization? The Medical Journal of Australia, n. 178, p. 9-12.

SANTOS, Boaventura de S. 2000a. A crítica da razão indolente: contra o desperdício da experiência. São Paulo: Cortez. 2000 b. Introdução a uma ciência pósmoderna. Rio de Janeiro: Graal. .2002a. Um discurso sobre as ciências. Porto: Afrontamento.

. 2002 b. Os processos de globalização. Disponível em: <www.eurozine.com/ article/2002-08-22-santos-pt.html>. Acesso em: 28 jan. 2005.
- (org.). 2004. Conhecimento prudente para uma vida decente: um discurso sobre as ciências revisitado. São Paulo: Cortez.

SMITH. Richard. 1995. The WHO: change or die. British Medical Journal, n. 310, p. 543-544.

SPINK, Mary J. 2000. Práticas discursivas e produção de sentidos no cotidiano: ap roximações teóricas e metodológicas. São Paulo: Cortez.

2004. Linguagem e produção de sentidos no cotidiano. Porto Alegre: EDPUCRS.

TRAVASSOS, Claudia; BUSS, Paulo. 2000. O polêmico relatório da Organização Mundial de Saúde. Cadernos de Saúde Pública, v. 16, n. 4, p. 890-891.

UNIVERSITY OF PITTSBURG. 2005. What is Global Health? Disponível em: <www. publichealth.pitt.edu/departments/c_g lobal_whatis.html>. Acesso em: 28 jan. 2005.

Department of Health and Human Services (EUA). 2005. What is Global Health? Disponível em: <www.globalhealth.gov/ faq.shtml $>$. Acesso em: 28 jan. 2005.

WHO (World Health Organization). 1946. Constitution of the World Health Organization. Disponível em: < policy.who.int/ cgi-bin/on_isapi.dll?hitsper-heading =on \&infobase $=$ basicdoc\&redord $\{\mathrm{C} 88\} \& \mathrm{soft}$ page $=$ Document $42>$. Acesso em: $17 \mathrm{jul}$. 2002.

1947. Chronicle of the World Health Organization. Disponível em: < whqlibdoc. who.int/hist/chronicles/chronicle_1948. pdf $>$. Acesso em: 15 jul. 2002.

_. 1978. Declaração de Alma-Ata. Conferência Internacional sobre Cuidados Primários em Saúde. Disponível em: < www. opas.org.br/coletiva/uploadArq/AlmaAta.pdf > . Acesso em: 12 nov. 2004. . 1998a. Health for all: origins and mandate. Disponível em: <www.who.int/ archives/who50/en/health4all.htm $>$. Acesso em: 16 dez. 2004. . 1998b. La Organización Mundial de la Salud cumple 50 años. Revista Panamericana de Salud Pública, v. 4, n. 4, p. 282-6.

2000. Informe sobre la Salud en el Mundo 2000: mejorar el desempeño de los sistemas de salud. Disponível: <www. 
who.int/whr/2000/en/whr00_en.pdf>. Acesso em: 15 jul. 2002.

.2002a. History of WHO and International Cooperation in Public Health. Disponível em: <www.who.int/aboutwho/ en/history.htm $>$. Acesso em: 20 abril 2002.

.2002b. Report of the Director-General 2001. Disponível em: <www. who. int/gb/ebwha/pdf_files/WHA55/ DRPTanglais.pdf $>$. Acesso em: 16 jan. 2005.

2002c. Proposed Programme Budget 2002/2003. Disponível em: <www.who. int/gb/e/e_ppb2002.html>. Acesso em: 15 jan. 2005.

2003. Measuring quality of life: the World Health Organization quality of life instruments (The WHOQOL-100 and The WHOQOL-BREF). Disponível em: <www.who.int/msa/qol/>. Acesso em: 24 mar. 2003.

W TO/WHO (World Trade Organization/ World Health Organization). 2002. World Trade Organization agre e ments \& Public Health: a joint study by the WHO and the WTO Secretariat. Disponível em: <www.who.int/media/homepage/ en/who_wto_e.pdf $>$. Acesso em: 15 jan. 2005.

YAMEY, Gavin. 2002. WHO in 2002: Have the latest re forms reversed WHO's decline? British Medical Journal, n. 325, p. 1.107-12.

Recebido em 05/07/2005

Aprovado em 18/07/2005 